\title{
The Structure of Method Section in Engineering Research Articles
}

\author{
Nurul Farahin Musa ${ }^{1}$, Noorli Khamis ${ }^{1} \&$ Jano Zanariah $^{1}$ \\ ${ }^{1}$ Centre for Language and Human Development, Universiti Teknikal Malaysia Melaka (UTeM), Malaysia \\ Correspondence: Nurul Farahin Musa, Centre of Languages and Human Development, Universiti Teknikal \\ Malaysia Melaka, Hang Tuah Jaya, 76100, Durian Tunggal, Melaka, Malaysia. Tel: 606-331-6957. E-mail: \\ farahin.musa@gmail.com
}

$\begin{array}{lc}\text { Received: January 16, } 2015 & \text { Accepted: January 28, } 2015 \quad \text { Online Published: June 5, } 2015 \\ \text { doi:10.5539/ass.v11n17p74 } & \text { URL: http://dx.doi.org/10.5539/ass.v11n17p74 }\end{array}$

\begin{abstract}
Genre analysis is one of the common ways to analyse the rhetorical structure of a text. Previously, there are many genre analysis and rhetorical organisation studies on research articles (RAs) from different disciplines. Some of them focused on the whole RAs and some of them focused on certain sections of the RAs. This study attempts to identify the moves in the Method section of the Engineering RAs, and the most frequent verbs in the moves. The present study adopts a corpus-based analysis; 60 RAs from an Engineering discipline were retrieved from the Scopus websites. The Method section framework from Huang (2014) was adopted for the analysis. The findings suggest that there are crucial moves in the Method section of the Engineering RAs, which need to be adopted by the writers to enhance not only their discourse competency, but also to meet the readers' expectation of the text readability.
\end{abstract}

Keywords: genre analysis, corpus-based study, research article, method section

\section{Introduction}

Research articles (RA) is one of the genres in academic writing; it is regarded as a medium to exchange and communicate new knowledge to the academic community members (Flowerdew, 2005; Kanoksilapatham, 2009). It involves the presentation of the research findings, and knowledge sharing among the academic community (Jusoff, Abdullah, \& Samah, 2009). However, writing a presentable RA for publication requires not only the awareness of the language use, but also the rhetorical organisation and features of the texts (Amnuai \& Wannaruk, 2013). These skills are referred as the discourse competency. Thus, it has been proposed that writers who wish to share their research findings with the academic community successfully should acquire the discourse competency (Bruce, 2009). They also need to be aware of differences in text structures to get their papers to be published in the international journals, and acquire international recognition (Zand-Vakili \& Kashani, 2012).

There have been numerous studies on the structure of RAs after Swales' (1990) introduction of the genre analysis of a text (Fazilatfar \& Naseri, 2014). Some of these studies focused on a certain section of the RAs (Alhuqbani, 2013; Peacock, 2011; Swales \& Najjar, 1987), and some on the whole structure of the RAs (Amnuai \& Wannaruk, 2013; Kanoksilapatham, 2005; Nwogu, 1997; Posteguillo, 1999).

Since research has become the main indicator for assessing performance among academics, researchers in universities are encouraged to conduct studies to develop new knowledge and innovation and exchange the findings among professional communities (Supatranont, 2012), Despite this fact, it is found that low English proficiency among NNES (Non-Native English Speakers) is one of the obstacles for the writers to publish their studies internationally (Supatranont, 2012). To counter this issue, a proper guidelines in writing the sections of the RAs in English should be developed to assist the writers in producing an impactful RA.

\section{Previous Studies on Method Section}

The Method section in RAs is the section that describes the procedures and experiments taken for obtaining findings for a study. It constitutes the key section in research papers because it serves to convince the readers on the validity of the procedures employed (Kallet, 2004; Lim. 2006). There has not been much studies on the Method section in previous research. According to Berkenkotter and Huckin (1995), the Method section has received less attention among the readers, and the number of studies on the Method section in this past few 
decades is considerably low. Moreover, these few researches focused on only a small number of RAs for a discipline (Peacock, 2011).

Nevertheless, Berkenttor and Huckin (1995) assert that the Method section is an interesting section in which the writers need to ensure that the explanations given about the experiments are presented adequately to the readers. Kanoksilapatham (2008) claims that there is no clear model for the Method section in all the RAs of all disciplines, as many researchers may not pay much attention to the section. The model of the Method section is different from the other sections in the RAs; for example, the Introduction section of any disciplines applies the common moves sequence of the Swale's framework (Move 1-2-3), but the Method section requires different patterns of rhetorical structure for different disciplines (Kanoksilapatham, 2003).

For Sociology RAs, Brett (1994) found that the Method section appears to have the main tasks as (1) describe how the data were obtained, (2) explain the concepts and variables in the study, and (3) state the statistical techniques to obtain results. Peacock (2011) conducted a study of the structure of the Method section in RAs across multiple disciplines and discovered that there are variations in the moves across the disciplines, apart from the common ones. Nwogu (1997), in her study of the rhetorical moves of medical RAs, identified three main moves in the Method section: Data Collection - Experiment - Data Analysis. In addition, there are sub-moves (steps) for each of the moves. For example, for the Data Collection move, the sub-moves include data source, data size and data collection criteria. Similarly, the Data Analysis move comprises the procedures for data classification and analysis of the data as the sub-moves.

However, in the engineering RAs, it is crucial to have a detailed investigation of the Method section, as it is an integral section in this discipline (Lim, 2006). A study of the biomedical engineering RAs, which adopted Swales' (1990) framework, reveals that the most crucial move in the Method section is Detailing methodological procedures in which the writers explain every step taken to obtain the results (Kanoksilapatham, 2005). However, Swales' framework was derived from the linguistics academic writing. Another framework, which is an extension of Swale's, was proposed by Nwogu (1997). However, Nwogu's framework was based on a scientific discipline i.e. medical RAs. Huang (2014), who adopted Nwogu's framework, identified four main moves in the medical RAs Method section (Table 1). It was also found that the writers of the medical RAs rarely include the explanation on the statistical methods used in their studies; they have the assumption that the readers would understand the terms and analysis method used in the Method section. From the same study, Huang also provides a new rhetorical structure for the Method section for the medical RAs (Table 1).

Table 1. The method moves from the previous studies

\begin{tabular}{|c|c|c|}
\hline Authors & Disciplines & Moves Proposed \\
\hline \multirow[t]{16}{*}{ Kanoksilapatham, 2012} & Biomedical Engineering & Move 1: Describing research procedures \\
\hline & & Step 1: Announcing objectives \\
\hline & & Step 2: Specifying protocolised procedures \\
\hline & & Step 3: Detailing methodological procedures \\
\hline & & Step 4: Providing background of procedures \\
\hline & & Step 5: Justifying a procedural decision \\
\hline & & Step 6: Declaring ethical statements \\
\hline & & Move 2: Featuring methodological issues \\
\hline & & Step 1: Describing participants, instruments, materials \\
\hline & & Step 2: Setting apparatus \\
\hline & & Step 3: Identifying data sources \\
\hline & & Move 3: Reporting and consolidating findings \\
\hline & & Step 1: Announcing findings \\
\hline & & Step 2: Interpreting findings \\
\hline & & Step 3: Comparing findings \\
\hline & & Step 4: Explaining findings \\
\hline \multirow[t]{3}{*}{ Nwogu, 1997} & Medical & Move 1 : Describing Data Collection Procedure \\
\hline & & Move 2 : Describing Experimental Procedure \\
\hline & & Move 3 : Describing Data-Analysis Procedure \\
\hline \multirow[t]{3}{*}{ Huang, 2014} & Medical & Move 1 : Describe study materials \\
\hline & & Step $1:$ Describing type of data collection \\
\hline & & Step $2:$ Describing the source for data collection \\
\hline
\end{tabular}




\begin{tabular}{cc}
\hline Authors & Doves Proposed \\
\hline Move $2:$ Provide inclusion criteria \\
Step $1:$ Describing the sample \\
Step $2:$ Describing the characteristics \\
Move $3:$ Describe procedures \\
Step $1:$ Taking the measurements \\
Step $2:$ Justifying the procedures \\
Move $4:$ Present the analysis of the experiment \\
Step $1:$ Statistical test techniques
\end{tabular}

Huang's work seems to suggest that an investigation on the rhetorical structure of the Method section of the biomedical engineering RAs using the newly devised framework may promise interesting findings, in addition to Kanoksilapatham's (2005). This paper attempts to carry out an investigation on a biomedical engineering RAs corpus using Huang's framework of the Method section. In other words, this paper intends to identify the structure of the Method section by using the framework based on the scientific discipline instead. Therefore, the objective of this study is to find the most frequent moves in the Method section of the biomedical engineering RAs. In addition, the most frequent verbs in the identified moves are also highlighted. The findings from this study offer an insight into the organisation of the Method section for RAs writing to enhance the writers discourse competency.

\section{Methodology}

\subsection{Corpus-based Study}

Corpus-based analysis is a commonly used tool in investigating the language use, characteristics and writing patterns in a text (Zhang, Pan, \& Zhang, 2014; Panah, Yunus, \& Embi, 2013). Corpus is a collection of texts, written or spoken stored in a computer application that is available for both qualitative and quantitative analysis (O'Keefe, McCarthy, \& Carter, 2007). Studies involving corpus analysis are increasing as the free software and internet-based tools are increasingly available on the internet (Flowerdew, 2008). Recently, many corpus-based studies have been conducted in identifying the macrostructures and linguistic features of RAs (Noorli, 2011). The present study uses a corpus of articles as a sample to investigate the rhetorical structures and linguistic feature of engineering RAs. According to Supatranount (2012), the corpus based method is useful for obtaining a real language sample, thus serving the needs of the target groups.

\subsection{Corpus}

For this study, 60 RAs from the biomedical engineering were selected for the corpus. Three journals of the engineering discipline were selected based on its impact factor (IF) (Kanoksilapatham, 2005). The journals were Biomaterials, Biomechnics and Modelling, and Journal of Biomechanics. All the RAs were retrieved from the Scopus website. Only articles with the IMRD (Introduction - Method - Results - Discussion) structure were selected for the corpus. In order to obtain the most frequent verbs for the Method section, Wordsmith Tool 6.0 was used (Scott, 2012).

\subsection{Genre Analysis}

Studies on the identification of the rhetorical structure of texts have gained more attention from researchers since the introduction of the Swales' (1990) framework. A genre has been defined as "a type of text or discourse designed to achieve a set of communicative purposes" (Swales, 1990). The ESP scholars define genre as a class of communicative events, such as a university lecture or an academic essay (Paltridge, 2001). In the Systemic Functional Linguistics, a genre is more often defined as a kind of text with related form, function and context, such as description, procedure or exposition. Paltridge (2001), and Suharno, Badib, and Sutopo (2011) define genre as the macrostructure and rhetorical function in their study of the introduction section.

It has been a concern to explain how texts are organized in systematic ways to present findings and messages by the writers, especially in academic genres. This is also the main focus for this study, i.e to identify the rhetorical moves for the Method section in the engineering RAs. According to Kanoksilapatham (2005), Swales (1990), and Upton and Connor, (2001), genre analysis refers to an analysis of texts in identifying the regularities of a structure that differentiate one type of text to another. Many previous studies in genre analysis have successfully provided guidelines to enhance writing an impactful research articles (Amnuai \& Wannaruk, 2013). 


\subsubsection{Move Analysis}

Swales' (1990) framework on the move analysis was intended to address the needs for the NNES writers to enhance their writing. At present, it is the commonly adopted framework to conduct investigations on the structural ognanisation of RAs. In this study too, the move analysis was adopted to identify the moves in the Method section of the biomedical engineering RAs. The analysis was based on the Method section framework proposed by Huang (2014). In Huang's (2014) framework, the Method section in the medical discipline consists of four main moves: (1) Describe study materials (2) Provide inclusion criteria (3) Describe procedures and (4) Present the analysis of the experiments.

\subsection{Inter-rater Reliability}

Inter-rater reliability is used to assess the degree to which different raters or observers make consistent estimates of the same situation. For the inter-rater analysis, three coders from the Language Department were chosen. A coding system of the moves and sub-moves, referred as steps in this study, was first devised; then, a 3-hour training session was conducted to ensure the coders understood how to code the sample texts using the coding scheme given (Kanoksilapatham, 2005). After the training, the coders were given 3 sets of the Method section excerpts to be coded independently. From various categorical variables for the move analysis, Cohen Kappa was chosen to assess the inter-rater reliability of the Method section for the articles. The percentage of agreement among the coders was computed as shown in Table 2. The result shows that the there is a high consistency $(98.4 \%)$ in the application of the coding system among the coders. This means that the devised coding system is a reliable tool for the tagging of the moves and steps in the study.

Table 2. Inter-rater reliability analysis in kappa value

\begin{tabular}{ccc}
\hline & Kappa Value & Percentage Agreement (\%) \\
\hline Method Section & 0.849 & 98.4 \\
\hline
\end{tabular}

\section{Results}

After analysing the text and identifying the moves for all the texts, the whole structure of the Method section for the biomedical engineering is described throughout this section. All the four moves for the medical RAs, as proposed in Huang's (2014) framework, did appear in the biomedical engineering RAs. Nevertheless, there are new steps identified in the biomedical engineering RAs.

\subsection{Results of Moves in the Method section}

\section{Move 1: Describing Study Materials}

Move 1 refers to the description of the materials used for the experiments of the study. This move basically consists of two steps: (1) Describing the type of data collection and (2) Describing the source for data collection. From the corpus, Move 1 appeared in only 16 RAs out of 60 , i.e. $27 \%$ from the whole corpus. This suggests that though the move does present in some RAs in the corpus, most writers did not include the move. In other words, Move 1 is optional in the RAs writing of this discipline. The following sample sentence (a) is an example of Step 1 to describe the type of data collected and selected for the study; while (b) is the source for the data collection, i.e. Step 2.

a) Brain tissue from post mortem human subjects (PMHS) was used in this study.

b) $\mathrm{BALB} / \mathrm{c}, \mathrm{DBA} / 1 \mathrm{~J}$ and C57/BL6 mice were purchased from SLC Japan and maintained under specific pathogen-free conditions.

\section{Move 2: Providing Inclusion Criteria}

Move 2 describes the samples and the characteristics required for the samples to be selected as a part of the experiments. This Move comprises two steps: (1) Describing the preparation of the sample and (2) Describing the characteristics required for the sample to be included in the experiment. This Move occurred in 52 RAs (87\%) out of the whole corpus. Sample sentences (c) and (d) demonstrate the steps respectively.

However, an additional step seems to be prominent in this corpus; there is a preliminary action on preparing the sample for the experiments. It appeared in all the 60 RAs (100\%) in the corpus. This step is not included in Huang's (2014) model. Sentence (e) is the sample of the step. 
c) During specimen preparation, the tissue was kept frozen, and between two preparation steps, it was stored in a double plastic layer.........

d) Subjects were excluded if they had a history of neck injury or pain, or known muscle, nerve, or balance problems.

e) Cells were expanded using standard cell culture methods in a humidified atmosphere containing 5\% $\mathrm{CO} 2$ at $37 \mathrm{C}$.

\section{Move 3: Describing Procedures}

This move describes the procedures taken in order to obtain the findings; it appeared in all the RAs (100\%) of the corpus. Thus, this signifies the importance of this move in the section. The finding corresponds with Kanosilapatham's (2005), who adopted the Swales' framework, i.e. Detailing methodological procedure. This move was also revealed as the most crucial move in his study. There are three steps for this move: (1) Taking the measurements and (2) Justifying procedures. It is also found that in Justifying the procedures, the most frequent words used in this step is because and to explaining why the measures and steps are taken. (f) and (g) are the examples for each step respectively.

f) ... Equilibrium stresses at $60 \%$ were determined by extrapolation of an exponential fit through the equilibrium stress strain data using a least squares optimization function $(\mathrm{R} 2=0.99)$

g) ... Local maxima were used to calculate the largest non-overlapping circles, with a minimum possible diameter of $\mathrm{D} 2 \ldots$

It is also apparent that some of the writers cited previous studies in this step. The step was identified in 52 RAs of the corpus (87\%). This step marks the distinguishing feature of the biomedical engineering RAs. (h) provides the sample of referring to previous studies.

h) $\quad . . . .$. the commonly used approach in which the stress free reference configuration B0 remains fixed throughout the growth simulation

\section{Move 4: Present Analysis of the Experiments}

Move 4 appeared in almost every RA of the corpus - 52 RAs out of 60 or $87 \%$. This move serves as a description of the statistical tests techniques and calculation for the data. In this move also, the software used and the justifications for their uses are provided. Move 4 is noted to be appearing in the last part of the Method section. (i) and $(\mathrm{j})$ are the examples.

i) Statistical differences among the experimental groups were evaluated by one way ANNOVA and Tukey's multiple comparison test.

j) Statistical tests were performed using SPSS IBM SPSS Statistics 19.

Table 3 summarizes the structure of the Method section identified from the corpus, with the addition of the two new steps: Describing the preliminary action and Referring to previous studies.

Table 3. Identified move structure of biomedical engineering RAs method section

Move 1 : Describe study materials

Step 1 : Describing the types of data

Step 2 : Describing source of the data

Move 2 : Provide inclusion criteria

Step 1 : Describing the sample

Step 2 : Describing the characteristics

Step 3 : Describing the preliminary actions

Move 3 : Describe procedures

Step 1 : Measurement taken

Step 2 : Justifying the procedures

Step 3 : Referring to previous studies

Move 4 : Present the analysis of the experiment

Step 1 : Statistical test techniques 


\subsection{Frequent Verbs in the Moves of the Method Section}

The basis of a language is its lexis (Noorli, 2011). Lewis (1993) argues that meanings are constructed from fixed words rather than fixed structures. Therefore, grammatical expressions are closely linked with the nature of the rhetorical structure of a text. The fixed grammatical expressions provide better understanding of the rhetorical intent of a structure; they reflect the rhetorical purpose of a structure (Bloch, 2010). Hence, this paper also identifies the most frequent verbs in the moves of the engineering RAs Method section.

Table 4 shows the top 10 most frequent verbs in the Method section. Kanoksilapatham $(2005,2012)$ asserts that the procedure in the Method section is described using past tense verbs (were obtained from, was added to, were removed). Though the list does not reveal the tenses of the verbs, the purpose of this list is to present the most frequently used verbs in the corpus regardless their forms and tenses. In other words, the verbs were selected based on their prototypical category. Table 5 displays the three most frequent verbs in each of the moves in the Method Section. The identified verbs reflect the rhetorical purposes they serve, for example, purchased, obtained and used to show describing the materials of the experiments or study. Further investigations on the linguistic features of the verbs can be conducted by observing the word cluster of each verb in the corpus (Table 6). The word cluster provides the most frequent structure the verbs assume in the corpus. From the 3-word clusters, it can be observed that most of the structures are in past tenses: was used to, were used to, was assumed to, were performed in, etc., and of passive constructions: assumed to be, was determined by, was calculated by.

Table 4. Most frequent verbs in the method section

\begin{tabular}{cll}
\hline No. & Word & Frequency \\
\hline 1. & used & 296 \\
2. & assumed & 134 \\
3. & performed & 134 \\
4. & obtained & 119 \\
5. & determined & 109 \\
6. & measured & 108 \\
7. & described & 105 \\
8. & incubated & 86 \\
9. & calculated & 80 \\
10. & washed & 76 \\
\hline
\end{tabular}

Table 5. The most frequent verbs in the moves of the method section

\begin{tabular}{llcc}
\hline \multirow{2}{*}{ Moves } & \multicolumn{2}{c}{ Top 3 verbs } \\
\cline { 3 - 4 } Move 1: & Describing study materials & Verbs & Frequency \\
& & obtained & 16 \\
& & purchased & 12 \\
Move 2: & Provide inclusion criteria & used & 9 \\
& & prepared & 28 \\
& & used & 22 \\
Move 3: & Describe Procedures & described & 19 \\
& & measured & 298 \\
& & described & 278 \\
Move 4: & Present the Analysis of the Experiments & assumed & 262 \\
& & using & 20 \\
\hline
\end{tabular}


Table 6. 3-word clusters of the top 10 most frequent verbs in the moves

\begin{tabular}{|c|c|c|}
\hline No & Cluster & Freq \\
\hline 1 & was used to & 49 \\
\hline 2 & were used to & 21 \\
\hline 3 & used as a & 12 \\
\hline
\end{tabular}

\begin{tabular}{clc}
\hline assumed & & \\
\hline No & Cluster & Freq \\
\hline 1 & assumed to be & 56 \\
2 & was assumed to & 28 \\
3 & is assumed to & 27 \\
\hline
\end{tabular}

\section{performed}

\begin{tabular}{cll}
\hline No & Cluster & Freq \\
\hline 1 & were performed in & 11 \\
2 & was performed using & 11 \\
\hline
\end{tabular}

determined

\begin{tabular}{cll}
\hline No & Cluster & Freq \\
\hline 1 & was determined & 18 \\
2 & was determined by & 12 \\
\hline
\end{tabular}

\section{described}

\begin{tabular}{cll}
\hline No & Cluster & Freq \\
\hline 1 & as described previously & 11 \\
2 & as previously described & 9 \\
\hline
\end{tabular}

calculated

\begin{tabular}{cll}
\hline No & Cluster & Freq \\
\hline 1 & was calculated as & 11 \\
2 & was calculated by & 10 \\
\hline
\end{tabular}

\section{obtained}

\begin{tabular}{clc}
\hline No & Cluster & Freq \\
\hline 1 & were obtained from & 22 \\
2 & obtained from the & 21 \\
3 & was obtained from & 10 \\
\hline
\end{tabular}

measured

\begin{tabular}{cll}
\hline No & Cluster & Freq \\
\hline 1 & was measured & 12 \\
2 & was measured by & 8 \\
\hline
\end{tabular}

\section{incubated}

\begin{tabular}{cll}
\hline No & Cluster & Freq \\
\hline 1 & were incubated with & 18 \\
2 & were incubated & 13 \\
\hline
\end{tabular}

\section{washed}

\begin{tabular}{cll}
\hline No & Cluster & Freq \\
\hline 1 & washed three times & 16 \\
2 & were washed & 12 \\
\hline
\end{tabular}

\section{Discussion}

Previously, Kanoksilapatham (2012) investigated the moves in the Method section of the biomedical engineering RAs by adopting Swales's moves, devised from the linguistics discipline. This study, provides a different perspective to the move analysis of the Method section of the biomedical engineering RAs by adopting Huang's (2014) model, which is derived from a technical/medical discipline.

The findings from the study reveals that though there are common moves in both the medical and biomedical engineering RAs, two new steps are identified in Move 2 (Step 3 - Describing the preliminary actions) and Move 3 (Step 3 - Referring to previous studies) of the biomedical engineering corpus respectively. It is found that one of the new steps identified, Step 3 - Describing the preliminary actions, forms an obligatory submove in Move 2. Another obligatory step for the biomedical engineering is Move 3 (Describing procedures), which is similar to the medical discipline, as well as Kanosilapatham's study. It is an important step in which the writers describe the procedures taken to allow replications of the procedure for future studies. These two newly identified obligatory steps distinguish the RAs of this discipline. Nevertheless, the finding also reveals that Move 1 is an optional move in the biomedical engineering RAs writing. Thus, the model is summarised in Table 3.

In addition, the analysis on the most frequent verbs in the Method section of the corpus reveals that the structures are mostly in past tenses and of passive construction. The 3 -word clusters of the verbs provide an insight into the 
most common fixed words in the Method section of the corpus. The fixed words reflect the rhetorical intent of the structure. These findings, hence, highlight the potential of empirical investigations into the structure and language use of RAs, especially of different disciplines, even sub-disciplines, for the purpose of discovering and enhancing discourse competency of the RAs writers (Panah, Yunus, \& Embi, 2013).

\section{Conclusion}

The RA writing consists of scientific communication elements, which depend heavily on the ability of the writer to use the appropriate structure and language in the fields. The main goal of writing an RA is to help the readers understand the concept and ideas that the writer intends to propose. Therefore, appropriate writing skills need to be acquired by writers to ensure the new knowledge that has been explored can be shared with the readers.

This study demonstrates that the rhetorical structure of an RA of a discipline can be analysed and understood from different frameworks. The findings provide another possible way of approaching the writing up of a biomedical engineering RA. In addition, the analysis of the verbs in the moves promises interesting insights into the most frequent fixed words to express the rhetorical intentions. The moves and fixed expressions in the moves identified in this empirical study can be highlighted in training NNES writers to prepare for their RA submission to prestigious journals.

\section{References}

Alhuqbani, M. N. (2013). Genre-Based Analysis of Arabic Research Article Abstracts across Four Disciplines. Journal of Educational and Social Research, 3(3), 371-382. http://dx.doi.org/10.5901/jesr.2013.v4n3p371

Amnuai, W., \& Wannaruk, A. (2013). Investigating Move Structure of English Applied Linguistics Research Article Discussions Published in International and Thai Journals. English Language Teaching, 6(2), 1-13.

Bloch, J. (2010). A concordance-based study of the use of reporting verbs as rhetorical devices in academic papers. Journal of Writing Research, 219-244.

Bruce, I. (2009). Results Section in Sociology and Organic Chemistry Articles : A Genre Analysis. English for Specific Purposes, 28, 105-124. http://dx.doi.org/10.1016/j.esp.2008.12.005

Fazilatfar, A. M., \& Naseri, Z. S. (2014). Rhetorical Moves in Applied Linguistics Articles and their Corresponding Iranian Writer Identity. Procedia - Social and Behavioral Sciences, 98, 489-498. http://dx.doi.org/10.1016/j.sbspro.2014.03.444

Flowerdew, L. (2005). An integration of corpus-based and genre-based approaches to text analysis in EAP/ESP: countering criticisms against corpus-based methodologies. English for Specific Purposes, 24(3), 321-332. http://dx.doi.org/10.1016/j.esp.2004.09.002

Flowerdew, L. (2008). Corpus-Based Analyses of the Problem-Solution Patterns. Amsterdam: John Benjamins.

Huang, D. (2014). Genre Analysis of Moves in Medical Research Articles. Stylus, 5(1), 7-17.

Jusoff, K., Abdullah, Z., \& Samah, S. A. A. (2009). Moving Ahead for Academic Excellence through International. International Education Studies, 2(2), 31-36.

Kallet, R. H. (2004). How to Write the Methods Section of a Research Paper. Respiratory Care, 49(10), 1229-1232.

Kanoksilapatham, B. (2003). A Corpus-Based Investigation of Scientific Research Articles: Linking Move Analysis with Multidimensional Analysis. Georgetown University.

Kanoksilapatham, B. (2005). Rhetorical structure of biochemistry research articles. English for Specific Purposes, 24(3), 269-292. http://dx.doi.org/10.1016/j.esp.2004.08.003

Kanoksilapatham, B. (2009). Generic Characterisation of Civil Engineering Research Article Abstracts. $3 L$ : The Southeast Asian Journal of English Language Studies, 19(3), 1-10.

Lewis, M. (1993). The Lexical Approach: The state of ELT and a way forward. England : Language Teaching Publication.

Lim, J. M. H. (2006). Method sections of management research articles: A pedagogically motivated qualitative study. English for Specific Purposes, 25(3), 282-309. http://dx.doi.org/10.1016/j.esp.2005.07.001

Noorli K. (2011). A Lexical Investigation of Engineering English: A Corpus-Based Approach. Universiti Kebangsaan Malaysia.

Nwogu, K. N. (1997). The Medical Research Paper: Structure and Functions. English for Specific Purposes, 
16(2), 119-138

O’Keefe, A., McCarthy, M., \& Carter, R. (2007). From Corpus to Classroom. Cambridge: Cambridge University Press.

Paltridge, B. (2001). Genre and the Language Learning Classroom. University of Michingan Press.

Panah, E., Yunus, M. M., \& Embi, M. A. (2013). Google-Informed Patter-Hunting and Pattern-Defining: Implication for Language Pedagogy. Asian Social Science, 229-238.

Peacock, M. (2011). The Structure of the Method Section in Research Articles Across Eight Disciplines. The Asian ESP Journal, 7(2), 97-124.

Posteguillo, S. (1999). The Schematic Structure of Computer Science Research Articles. English for Specific Purposes, 18(2), 139-160. http://dx.doi.org/10.1016/S0889-4906(98)00001-5

Scott, M. (2012). WordSmith Tools.

Suharno, Badib, A. A., \& Sutopo, D. (2011). Rhetorical Functions in the Introduction Section of English Research Articles by Non-Native Speakers.

Sun, J., \& Shang, L. (2010). A Corpus-based Study of Errors in Chinese English Majors' English Writing. Asian Social Science, 6(1), 86-94. http://dx.doi.org/10.5539/ass.v6n1p86

Supatranont, P. (2012). Developing a writing template of research article abstracts: A corpus-based method. Procedia - Social and Behavioral Sciences, 66, 144-156. http://dx.doi.org/10.1016/j.sbspro.2012.11.256

Swales, J. (1990). Genre Analysis : English in Academic and Research Settings. Cambridge University Press.

Swales, J., \& Najjar, H. (1987). The Writing of Research Article Introductions, 4(2), 175-191.

Upton, T. A., \& Connor, U. (2001). Using computerized corpus analysis to investigate the textlinguistic discourse moves of a genre \$, 20 (August 1999).

Zand-Vakili, E., \& Kashani, A. F. (2012). The Contrastive Move Analysis: An Investigation of Persian and English Research Articles 'Abstract and Introduction Parts. Mediterranean Journal of Social Sciences, 3(2), $129-138$.

Zhang, Y. (2014). A corpus based analysis of lexical richness of Beijing Mandarin speakers: variable identification and model construction. Language Sciences, 44, 60-69. http://dx.doi.org/10.1016/j.langsci. 2013.12.003

Zhang, X., Pan, Y., \& Zhang, M. (2014). Superstructure Analysis in News Stories-A Contrastive Study of Superstructure in VOA, BBC, and NPR News. Asian Social Science, 199-209.

\section{Copyrights}

Copyright for this article is retained by the author(s), with first publication rights granted to the journal.

This is an open-access article distributed under the terms and conditions of the Creative Commons Attribution license (http://creativecommons.org/licenses/by/3.0/). 